\title{
Ability to Keep Pace With The Times To Innovative Benefit Of High-End Hotel In Lijiang Area
}

\author{
Ding Li \& Shangcheng Zhang\& Xiaoning He \& Shengfei Bi\& Hao Zhang ${ }^{1}$, \\ Aiping $\mathrm{Li}^{2}$ \\ ${ }^{1}$ Tourism and Culture College of Yunnan University, Lijiang 674100, China \\ ${ }^{2}$ Faculty of Information Engineering and Automation, Kunming University of Science and Technol- \\ ogy, Kunming 650504, China
}

Keywords: Perception, customer demand, Innovative products, learn knowledge

\begin{abstract}
Using the statistical case study method based on knowledge management, to explore the effect that the ability to keep pace with The Times have on innovative benefit. Take several highend hotels in Lijiang area for example, resolve the three dimensions of the hotel' ability to keep pace with The Times by using content analysis software etcML to encode- perception ability of the customer requirements, the ability to innovate products and hotel organization learning ability, so as to build a model for the effect that the ability to keep pace with The Times have on innovative benefit of the hotel, then use large sample survey data for empirical testing. The research show that: the three dimensions of the ability to keep pace with The Times have a significant positive influence on hotel's innovative benefit.
\end{abstract}

\section{INTRODUCTION}

Over the years of reform and opening up, China's hotel industry develop rapidly and the industry expand constantly. However, as the market being saturated, great changes occurred in the hotel's business environment. As the trend of economic globalization has strengthened, accelerated change in the emerging IT technology as the representative, as well as the increasingly diverse customer demands have exacerbated the hotel market competition. How the hotel's way of life and the development model adapt to the new challenge raised by the market?

The traditional resource-dependence theory emphasizes the dependence on external resources, while the resource-based theory emphasizes the importance of the enterprise's own resources and capabilities. The theory holds that the traditional view of resource is static, while enterprises that want to remain competitive in a dynamic market environment must be dynamically adjust resources and reconstruct the ability to adapt to environmental changes. This is also about how the advancing development theory explains this article from the perspective of the times the possible way to study on how the hotels improve the innovation performance. The enterprise's ability to acquire absorbs, create, integrate and reconstruct knowledge; the ability to respond to environmental changes; the ability to integrate, create and configure internal and external resources.

Hindertje Hoarau discusses openness in experience-based tourism and proposes a framework for open innovation in knowledge plays an essential role in innovation processes, and the epistemological assumptions about knowledge influence the perception of innovation processes(Hindertje Hoarau). Staci M Zavattaro offers managers a road map for successful innovation implementation and benefit researchers by providing clarity into the antecedents of the innovation capability with the destination marketing organizations context(Zavattaro). Joshua J. Daspit integrate organizational capabilities into the place branding process to showcase how a lead destination marketing organization (DMO) can influence a customer-based brand equity outcome(Joshua J. Daspit) Caroline Orchiston examines organizational resilience in a post-disaster context and provides a quantitative assessment of tourism organizational resilience and compares organizational resilience within three tourism sub-sectors(Caroline Orchiston). Alexandra V. Michailidou presents a generic methodological framework to plan, manage and implement climate change mitigation and adaptation measures in the tourism context(Alexandra V. Michailidou). Levent Altinay identifies the resource needs of a 
tourism social enterprise and evaluate the means by which these resources are mobilized(Levent Altinay). Zhang, Jiekuan contributes a theoretical framework and approach for the determination of top priorities in tourism development and making decisions based upon that approach(Zhang, Jiekuan). Doris O. Gomezelj presents a systematic review of the literature, different research approaches and perspectives on tourism innovation and offers a synthesis findings; and provides a discussion and proposals for future research(Doris O. Gomezelj). Hjalager delivers a critical review of the conceptualizations of value chains in tourism(Hjalager). Lee examines innovation, entrepreneurial self-efficacy and human capital as predictors of restaurant performance (Lee).

Although different scholars divide dynamic capabilities in different dimensions, its purpose is to make the in-depth analysis could make the enterprise maintain the competitive advantage in keeping pace with the Times.

In this paper, the investigation statistical analysis based on knowledge management study on the effect that the ability to keep pace with time has on hotel's innovation performance. The reasons are as follow: Firstly, Case study method is considered to be one of the most appropriate tools for early detecting and constructing new theory, which can help the researchers to explore the connotation and relationship of the core construct in specific situation; Secondly, foreign mature is usually used in empirical study, and the study is easy to separate from management practices of Chinese enterprises because foreign mature is lack of local applicability. The article integrated the advantages of the two kinds of research method, first by exploratory case study and adopting encoding method can resolve the structure dimension of hotel's ability to keep pace with the times. Make a framework for the influence mechanism of innovation performance, and finally using statistics from the large sample survey to test the framework of the research hypothesis.

\section{SINGLE CASE STUDY}

\subsection{Case Section}

This article selects representative in LIJIANG's high-end hotel industry in recent years------Banyan Tree Hotel, Treasure Harbour Hotel, Pullman Resort for the study. These hotels achieve rapid growth in recent years, its operating performance improve steadily. Achieving such rapid growth in a rapidly changing market environment could partly show their ability to keep pace with the time have a certain degree of influence on its economic improvement.

\subsection{Data Collection}

The main source of information on the case include: First, secondary sources, including books, periodicals, databases and other documents, as well as the public conversation from Banyan Tree Hotel, Treasure Harbour Hotel, Pullman Resort in newspaper and networks. Second, three of LIJIANG's chain hotel, Banyan Tree Hotel, Treasure Harbour Hotel and Pullman Resort got field interview mainly from July to August in 2015.Before the interview, a research outline is designed for the relevant content of the hotel's ability to keep pace with the Times, and adjusted according to the actual situation of the interviews, finishing a large number of data focusing on enterprises' ability to advance with the Times. Third, achieves and files including internal information, publications, staff training information etc.

\subsection{Code Analysis}

This paper uses the content analysis software etcML to deal with the collected data, using the social network, semantic network and analysis function to parses out 25 high frequency keywords, linking these words according to the co-occurrence degree and correlation, and adopt the method of sequential coding to extract the key dimensions variable of hotel's capacity to keep pace with times.Specifically:require(22\%),sense(23\%),expected(31\%), estimation(15\%),customer(21\%), feelin $\mathrm{g}(21 \%)$,expectation(18\%), claim(12\%) as customers' perception; will be particular(12\%), innovation(29\%), service(27\%), smile(45\%), product(31\%), satisfaction(26\%),improvement(24\%), environment(25\%), those as product innovation; study will (32\%), imitation(11\%), comparison(12\%), organization(24\%), communication (33\%) as organization learning. Then, communicate with the senior manager from the Banyan Tree Hotel, Treasure Harbors Hotel and Pullman Resort by visit- 
ing or calling, determine the accuracy of the three key dimensions of the ability to keep pace with the times--- awareness of customer demand, product innovation and the ability to organize and learn. Among them, the awareness of customer demand is the market response ability for the enterprise to sense the environmental changes and understand customer's need. Enterprise with the awareness of market respond the changing market opportunities and threat by scanning, finding, exploring and adapting. Product innovation refers to enterprise's adaption to the changing environment and customer demand, turning the knowledge obtained from outside into new product, new service or new process to achieve enterprise appreciation with the differentiated competitive advantage. Organizational learning ability refers to reflecting the relationship of a continuous 'dialogue (interactive)' between the enterprise and the customer in perspective of key process.

\section{EMPIRICAL ANALYSIS}

\subsection{Measuring Scale}

In combination with related literature, 28 questionnaires have been carried out after carding and reviewing the relationship between the resolved key dimensions of the ability to keep pace with The Times and innovated efficiency in theory. After testing the reliability of the scale, results show that the cronbachsa coefficient values of the overall scale and sub scale are over 0.8 in average, which means that the questionnaires have good reliability. Then, questionnaire haven been sent out in a large scale, concentrated in Lijiang Dayan Ancient Town and Shuhe Ancient Town. Afterwards, 512 questionnaires have been distributed, 313 of them were recycled and 298 were valid, and the recovery rate of the effective questionnaire is $58.2 \%$, which meet the need of research. According to the recycled effective questionnaire, the sample from high-end, middle-end, and midrange-andhigh-end have an account for $63.9 \%, 6.1 \%$ and $10 \%$ respectively.

First, the innovation performance scale. According to the maturity scale of tourism enterprise innovation activities and the on-the-spot interview of Banyan tree hotel, Treasure Harbour Hotel and Pullman Resort in Lijiang area from the author, design a question in the use of component aggregation method about the evaluation standard of the hotel innovation efficiency. Title of the question is' Compared with the average level of the development of the domestic hotel industry, the implementation effect in the aspect of innovation of your company. Specific include:1. New or significantly improved products and service used in recent three years.2. Compared with competitors, our hotel launch more new products or new services.3. Compared with competitors, our hotels' new products or new services have a higher rate of success.4.The new product or service we use could meet the personalized needs of customers more compared with competitors.5.The new product and service we use could meet and exceed customer's demand for new products.6.Estimate whether the new product and service adopted by our hotel have an higher customer satisfaction than our competitors.NO=0,YES=1, to sum up the score, score range from 0-9,the higher the score, the higher the hotel's innovation efficiency.

Second, The scale of the ability to keep pace with The Times. According to the high frequency keywords of the hotel's ability to keep pace with The Times parsed out by case code, through group discussion, expert interview, literature analysis, etc. , formed 10 observation variable aiming at three key dimensions of the ability to keep pace with The Times(Customer awareness, produce innovation and organizational learning ability).,as shown in Table 1.

Have a reliability test and validity test on the scale of the ability to keep pace with The Times and the scale of the innovation benefits. Use the SPSS13.0software to analyze the correlation coefficient of each item. The test results show that the correlation coefficient of factors within is high (over 0.500), instructing that the convergent validity of the scale is higher; the correlation coefficient of different factors of each item is low(less than 0.400 ), indicating that the difference between the validity of the scale is high.

In the hotel industry, not the customers to buy their products, but by the purchase of services to meet their needs. The customer really care about is whether the product or service provided by the hotel to their expectations. Customer demand is a service enterprise product innovation or service a 
core source of innovation and motivation. The hotel's innovative ability and customer loyalty in this business are closely related, and pointed out that the higher the customer loyalty, the stronger the innovation ability of the hotel. Therefore, the hotel service innovation in the process of customer participation should be more strong, customer participation and customer behavior, attitude and ability of hotel service innovation has a significant impact, the hotel to the customer demand for accuracy and timeliness of perception has important effects on the innovation of the hotel benefit. On this basis, this paper puts forward hypothesis: positive influence on customer perceptions of hotel innovation efficiency $\left(\mathrm{H}_{\mathrm{F}}\right)$.

Currently, China's hotel market has formed many brands of competition pattern. Each hotel exists serious homogeneity in the market positioning, price, product design etc. for comparison another thus leading to fierce competition among them. To emphasize the difference of innovation is the solution out of the hotel's development. Hotel should reflect its brand positioning and brand uniqueness through innovation. In addition to the hotel should attract customers with brand connotation thus enhancing brand competitiveness. Therefore in the face of the growing demand for the customer, the hotel needs to view the customer's demand as the essence to carry on the differentiation of innovation through providing efficient service to improve the hotel's level of service and customer satisfaction constantly. Based on this, this paper puts forward the hypothesis $\mathrm{H}_{\mathrm{C}}$ : the innovative ability of product/service positively influences the benefit of the hotel.

Table 1 The Scale of the Hotel's Ability to Keep Pace with The Times

\begin{tabular}{|c|c|c|}
\hline Dimension & Observational variable & High-frequency words \\
\hline \multirow{3}{*}{$\begin{array}{l}\text { Customer } \\
\text { Awareness } \\
\text { Capability }\end{array}$} & $\begin{array}{l}\text { Our hotel can quickly understand the } \\
\text { status of the leading technology prod- } \\
\text { ucts or service of the industry }\end{array}$ & \multirow{3}{*}{$\begin{array}{l}\text { Demanding (21\%), Feeling (20\%), } \\
\text { Expected (33\%), Estimation (12\%), } \\
\text { Customer (19\%), Feelings (20\%), } \\
\text { Expectation (19\%), Requirement (11\%) }\end{array}$} \\
\hline & $\begin{array}{l}\text { Our hotel can understand and get the } \\
\text { customer's demand info quickly and } \\
\text { effectively }\end{array}$ & \\
\hline & $\begin{array}{c}\text { Our hotel will be able to identify } \\
\text { changes and development trend of the } \\
\text { industry quickly. }\end{array}$ & \\
\hline \multirow{3}{*}{$\begin{array}{l}\text { Product } \\
\text { Innovation } \\
\text { Capability }\end{array}$} & $\begin{array}{l}\text { Our hotel can launch a new product of } \\
\text { service according to the changing de- } \\
\text { mand of the market }\end{array}$ & \multirow{3}{*}{$\begin{array}{c}\text { Special (10\%), Innovation (27\%), } \\
\text { Service (23\%), Smiling (40\%), } \\
\text { Product (28\%), Satisfaction (25\%), } \\
\text { Improved (14\%) }\end{array}$} \\
\hline & $\begin{array}{l}\text { The new product or service launched } \\
\text { by our hotel can form obvious differ- } \\
\text { ence with competitors on forming our } \\
\text { core competitiveness } \\
\end{array}$ & \\
\hline & $\begin{array}{l}\text { Our hotel is able to let the employees } \\
\text { understand and master new } \\
\text { knowledge from the outside quickly. }\end{array}$ & \\
\hline \multirow{4}{*}{$\begin{array}{l}\text { Organizational } \\
\text { Learning } \\
\text { Capability }\end{array}$} & $\begin{array}{l}\text { Our hotel is able to understand the sat- } \\
\text { isfaction that the customer have on } \\
\text { our new product or service. }\end{array}$ & \multirow{4}{*}{$\begin{array}{c}\text { Learning (31\%), Imitation (9\%), } \\
\text { Organization (22\%), Communication (30\%), Im- } \\
\text { proved (17\%), Development (12\%), Absorption } \\
\text { (11\%), }\end{array}$} \\
\hline & $\begin{array}{c}\text { Our hotel can adjust or improve our } \\
\text { product or service quickly according } \\
\text { to customer's requirement. }\end{array}$ & \\
\hline & $\begin{array}{l}\text { Customers are able to participate in } \\
\text { our process of launching new product } \\
\text { or service, }\end{array}$ & \\
\hline & $\begin{array}{l}\text { Our hotel pay special attention to the } \\
\text { management and maintain of custom- } \\
\text { er info }\end{array}$ & \\
\hline
\end{tabular}


The connection between a tourism enterprise and its external partners is very important to a tourism organization maintaining innovative abilities. The tourism organization gets, manages, collects and learns customer information that have significant meaning to its innovation. This paper considers that the organizational learning of the hotel is consists of a serials operational process that hotel should communicate with external partners, customers and other stakeholders continuously. Thus new products, services and applications will be developed in the process of the input, output and feedback of information flow among stakeholders. So this paper puts forward a hypothesis: the leaning ability of organization can influence on innovative benefit of a hotel

activelv $\left(\mathrm{H}_{\mathrm{r}}\right.$.).Based on the above assumptions, the paper's abilitv to build the hotel advancing

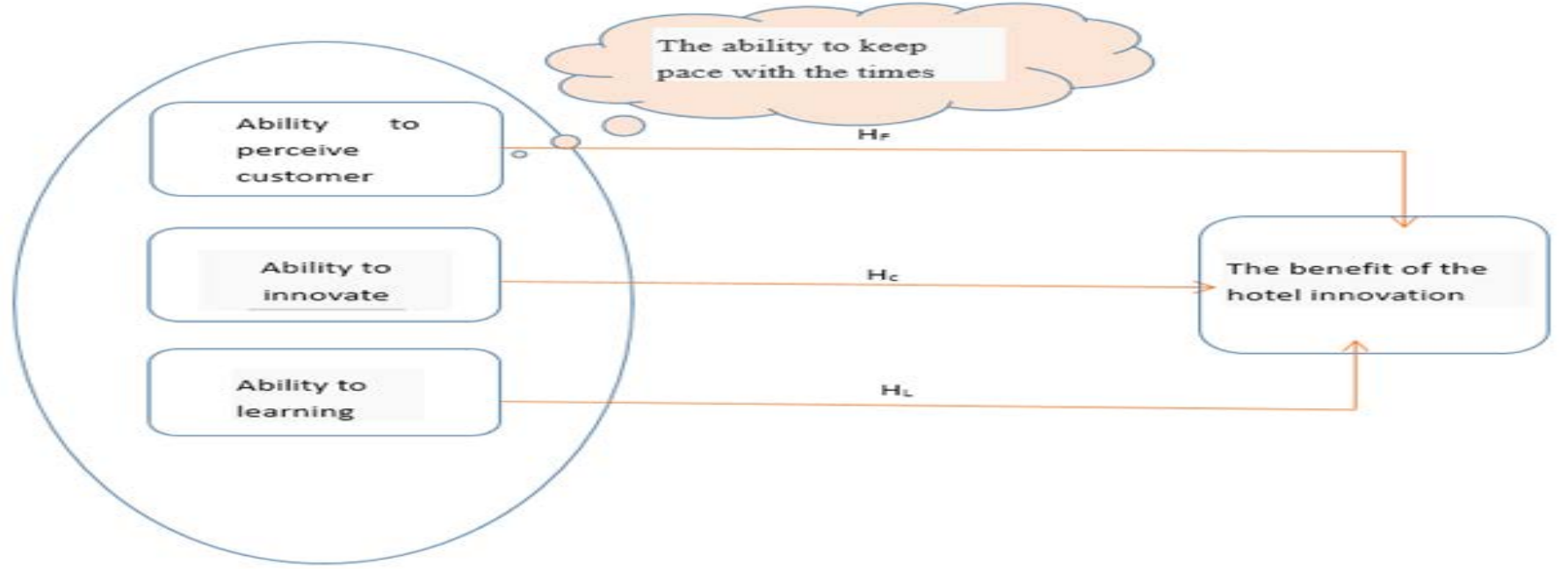

Figure. 1 Function Model of the Ability of Keeping Pace with the Times to Innovate the Hotel

\subsection{Regression Results}

This paper is divided into two steps to test the abilities of the hotel to keep pace with times that impact the innovative performance of hotel. In order to meet the requirements of hypothesis testing, a total of 2 models are set up. The explanatory variables of the model 1 and the model 2 are the innovative benefit of the hotel. As the basis model, model 1 only includes the control variables, no independent variables; Based on the model 1, the model 2 increase the ability to keep pace with the times that are consist 3 independent variables: one is the perceptive ability to the demand of customer; the another is the innovative ability to develop products; the third is learning ability for tourism organizations. These 3 independent variables will be tested the degree of the impact to the innovative performance of hotel on the 3 dimensions.

Enterprise scale (number of employees) is the internal power that affects the benefit of the enterprise. Therefore, we make it as a control variable introduced the model 1 . F value of Model 1 is $0.715, \mathrm{R}^{2}$ value is 0.017 , The adjusted $\mathrm{R}^{2}$ value is -0.0038 , It show that the overall fitting effect of model 1 is poor, and cannot explain the dependent variable well. We have added three dimensions of the ability of the times on the basis of model 1 as independent variables. Thus formed model 2.The three dimensions are: The ability to perceive customer demand, the ability to innovate products and the ability to organizational and learning. The explanatory power of the model 2 has been greatly improved. The value promoted to 19.832 and significantly $(\leqslant 0.001)$. $\mathrm{R}^{2}$ value and the adjusted $\mathrm{R}^{2}$ values were 0.374 and 0.381 . The results show that the fitting effect of the model 2 is good. The regression results of the model 1 and model 2 are shown in Table 2. 
Table 2 Regression analysis results

\begin{tabular}{|c|c|c|c|}
\hline & Variables & Model 1 & Model 2 \\
\hline \multirow{2}{*}{$\begin{array}{c}\text { Control varia- } \\
\text { bles }\end{array}$} & Enterprise scale & -0.029 & 0.137 \\
\cline { 2 - 4 } & Enterprise establishment time & 0.068 & -0.106 \\
\hline \multirow{3}{*}{$\begin{array}{c}\text { Independent } \\
\text { variables }\end{array}$} & Customer demand perception & & 0.264 \\
\cline { 2 - 4 } & The ability to innovate products & & 0.312 \\
\cline { 2 - 4 } & The ability to organizational and learning & & 0.247 \\
\cline { 2 - 4 } $\begin{array}{c}\text { Regression re- } \\
\text { sults }\end{array}$ & F value & 0.715 & 19.832 \\
\cline { 2 - 4 } & $\mathrm{R}^{2}$ & 0.017 & 0.374 \\
\hline
\end{tabular}

There are 3 significant positive correlation respectively between innovation of the hotel and perception of the demand of customer, developing Innovative products and organizational learning skill from Table 2. Correlation coefficients were 0.252（ $\mathrm{P} \leqslant 0.010 ）, 0.293(\mathrm{P} \leqslant 0.001)$ and 0.235

$(\mathrm{P} \leqslant 0.010)$ respectively. These 3 pair's factors have positive affection to the innovative performance of hotel significantly. Although these 3 pairs factors own different degree of influence. Therefore the hypothesis of $\mathrm{H}_{\mathrm{F}}, \mathrm{H}_{\mathrm{C}}$ and $\mathrm{H}_{\mathrm{L}}$ have been verified.

\section{SUMMARY}

The research of innovative management at hotel enterprise in China is still in its infancy. There are few articles were found from the views of the ability to keep pace with the times.

There are 3 aspects to show the abilities of the hotel to keep pace with times: to perceptive the demand of customer, to develop Innovative products and organizational learning skill. These 3 factors affect the innovative performance of hotel significantly.

\section{ACKNOWLEDGEMENTS}

The research work was supported by Foundation of Bureau of Science and Technology Lijiang, Yunnan Provincial under Grant No. ljs2013-09 and scientific research foundation of Tourism and Culture College of Yunnan University under Grant No. 2013xy08.

\section{REFERENCES}

[1]. Altinay, Levent, Marianna Sigala, and Victoria Waligo. "Social value creation through tourism enterprise." Tourism Management 54 (2016): 404-417.

[2]. Gomezelj, Doris O. "A systematic review of research on innovation in hospitality and tourism." International Journal of Contemporary Hospitality Management 28.3 (2016).

[3]. Hjalager, Anne-Mette, Kaarina Tervo-Kankare, and Anja Tuohino. "Tourism value chains revisited and applied to rural well-being tourism." Tourism Planning \& Development (2016): 117.

[4]. Hoarau, Hindertje. "Open Innovation in the Tourism Experience Sector: The Role of Practice Based Knowledge Explored." Open Tourism, 2016. 137-152. Berlin Heidelberg: Springer.

[5]. J. Daspit, Joshua, and Staci M. Zavattaro. "Integrating innovation and absorptive capacity into the place branding process: a capability-based perspective." Journal of Place Management and Development 7.3 (2014): 206-224. 
[6]. Lee, Craig, Rob Hallak, and Shruti R. Sardeshmukh. "Innovation, entrepreneurship, and restaurant performance: A higher-order structural model." Tourism Management 53 (2016): 215228.B

[7]. Michailidou, Alexandra V., Christos Vlachokostas, and Nicolas Moussiopoulos. "Interactions between climate change and the tourism sector: Multiple-criteria decision analysis to assess mitigation and adaptation options in tourism areas." Tourism Management 55 (2016): 1-12.

[8]. Orchiston, Caroline, Girish Prayag, and Charlotte Brown. "Organizational resilience in the tourism sector." Annals of Tourism Research 56 (2016): 145-148.

[9]. Zavattaro, Staci M., and Joshua J. Daspit. "A grounded theoretical approach to understanding innovation in destination marketing organizations." Journal of Vacation Marketing (2016): 1356766715623826.

[10]. Zhang, Jiekuan. "Weighing and realizing the environmental, economic and social goals of tourism development using an analytic network process-goal programming approach." Journal of Cleaner Production (2016). 